\title{
Pentingnya Materi Lingkungan Terhadap Pembelajaran Bahasa Indonesia
}

\author{
Anisa Luthfiana \\ Universitas Negeri Padang FBS \\ anisaluthfiana090@gmail.com
}

Lingkungan merupakan hal yang penting dan berkaitan dengan kehidupam masingmasing individu. Keadaan lingkungan sangat berpengaruh terhadap pribadi seseorang. Pada kegaiatan pembelajaran, keadaan lingkungan sangat berpengaruh terhadap hasil dari pembelajaran tersebut. Sehingga beberapa materi yang berkaitan dengan lingkungan sebaiknya diberikan pada kegiatan pembelajaran. Pada kegiatan pembelajaran bahasa Indonesia, materi lingkungan juga memberikan dampak pada peserta didik. Materi lingkungan menjadikan siswa lebih peka dan peduli terhadap lingkungan, terutama pada lingkungan kelas saat kegiatan pembelajaran bahasa Indonesia.

Lingkungan sangat mempengaruhi segala hal yang mencakup dalam kehidupan kita. Menurut (Ramadhan, et al.,(2019) mengatakan bahwa setiap Individu memiliki kewajiban yang sama untuk melindungi lingkungan. Selain itu, Lai CS ( dalam Ramadhan, et al, 2019) mengatakan bahwa "environmental problems are inherently inseparable from environmental awareness, values, and attitudes of people. This encourages countries to start assessing environmental education". Masalah lingkungan tidak dapat dipisahkan dari kesadaran masyarakat terhadap lingkungan. Hal ini dapat dijadikan pemerintahan sebagai pendorong untuk mulai menilai pendidikan lingkungan. Salah satu masalah yang sering terjadi adalah kebersihan lingkungan sekitar. Masyarakat kurang menyadari bahwa tindakannya tersebut bisa merusak lingkungan. Menurut Cokcaliskan dan Celiko (dalam Ramadhan at al, 2019) individu harus didorong untuk tidak memandang lingkungan sebagai sesuatu yang harus dieksploitasi untuk tujuan mereka, tetapi sebagai aseta yang berharga yang harus dilindungi demi kelangsungan hidup manusia.

Sukma(2016) Unesco melaporkan tingkat penguasaan bahan ajar dan keterampilan dalam menggunakan metode mengajar yang inovatif masih kurang, umumnya guru menggunakan metode ceramah . Ramadhan, Asri dan Indriyani ( 2018) model pembelajaran yang inovatif mampu meningkatkan hasil belajar peserta didik. Melalui pendidikan lingkungan ini bisa membantu guru dalam menyampaikan materi pembelajaran kepada siswa.

Menurut Ramadhan, Sukma, dan Indriyani(2019) guru berperan penting dalam pengajaran pendidikan lingkungan dan menumbuhkan kesadaran siswa tentang lingkungan.Sukma (2015) Interaksi belajar-mengajar yang terjadi di dalam kelas merupakan interaksi timbal-balik antara guru dengan siswa maupun guru dengan siswa-siswa. Guru juga memiliki peranan yang penting dalam mengajarkanmateri lingkungan kepada siswa. Guru juga harus mengembangkan kemampuan siswa dalam memahami, mengkritik, dan berpartisipasi secara rasional dalam setiap wacana tentang masalah lingkungan. Dalam pembelajaran bahasa Indonesia guru pasti memiliki kendala dalam proses pembelajaran terutama pada aspek kognitif, yaitu kurangnya pemahaman 
guru dalam mengajar (Sukma, 2019). Melalui pendidikan lingkungan ini bisa membantu guru dalam menyampaikan materi pembelajaran kepada siswa. Misalnya, saat siswa ditugasi dalam membuat teks eksposisi yang bertemakan lingkungan, seorang guru bisa menyuruh siswanya mengamati lingkungan disekitarnya agar bisa menghasilkan teks eksposisi yang bagus. Menurut Unyar dan Ensar (dalam Ramadhan et al,2019) penggunaan tema lingkungan dalam pembelajaran teks dapat memicu minat belajar bahasa siswa dan secara implisit dapat meningkatkan pengetahuan siswa tentang lingkungan.

Materi lingkungan yang diberikan dan diajarkan disekolah maupun perguruan tinggi merupakan langkah awal yang baik bagi para ahli pendidikan yang perlu diapresiasi, dengan mempelajari materi lingkungan dari dini maka dapat menumbuhkan kepedulian akan pentingnya dan melestarika lingkunga. Menurut Ramadhan, et al (2019) mengemukan pendidikan lingkungan penting untuk meningkatkan sikap dan kesadaran siswa terhadap lingkungan.

Menurut Ramadhan,Sukma, dan Indriyani(2019)siswa perlu memiliki pengalaman yang baik dalam memahami dan mengatasi setiap perubahan global dan lingkungan masyarakat. Menurut Ramadhan Sukma, dan Indriyani(2019)agar siswa berpatisipasi dalam melindungi lingkungan, penting untuk mengembangkan pengetahuan tentang lingkungan, kesadaran lingkungan dan perubahan perilaku terhadap lingkungan.Safitri dan Sukma (2020) pemilihan sumber belajar harus sesuai dengan karakteristik siswa agar sumber belajar yang digunakan dapat menunjang kemampuan siswa dalam belajar secara optimal.

Berdasarkan permasalahan diatas, penulis sudah menyebarkan angket mengenai pentingnya materi lingkungan terhadap pembelajaran bahasa Indonesia yang diberikan kepada mahasiswa UNP dan UNAND S1 semester 5 Tahun 2020. Penilian yang dilakukan dengan membuat sepuluh pernyataan tentang pentingnya materi lingkungan terhadap pembelajaran bahasa Indonesia dalam bentuk angket google form. Hasil yang didapat dari penelitian tersebyt adalah sebagai berikut. Pernyataan pertama, lingkungan sangat berpotensu untuk mengubah pola pikir dan pola laku siswa, menyatakan sangat setuju (58,8\%), setuju (41,2\%), kurang setuju ( $0 \%)$, dan tidak setuju (0\%). Pernyataan kedua, materi teks lingkunganmerupakan sebuah strategi pembelajaran Bahasa Indonesia berkaitan dengan penggunaan bahasa Indonesia dalah kehidupan sehari-hari, menyatakan setuju (75\%), menyatakan setuju (22,5\%), menyatakan sangat tidak setuju (2,5\%), dan tidak setuju (0\%). Pernyataan ketiga, materi teks lingkungan dalam pembelajaran bahasa Indonesia yang diterapkan kepada peserta didik agar dapat mengembangkan pola pikir dan bertindak, berprilaku sehat secara mental dalam kehidupan sehari-hari, menyatakan setuju (55\%), sangat setuju (40\%), tidak setuju (5\%), dan sangat tidak setuju ( $0 \%)$.. Pernyataan keempat, lingkungan merupakan faktor yang mempengaruhi dalam pelaksanaan kegiatan pembelajaran bahasa Indonesia, menyatakan setuju (55\%), setuju (45\%), tidak setuju ( $0 \%)$, dan sangat tidak setuju ( $0 \%)$. Pernyataan kelima, pada pembelajaran bahasa indonesia pendidik harus memberikan pentingnya materi lingkungan untuk menjaga kelestarian lingkungan,menyatakan setuju (76,5\%), sangat setuju (23,5\%), tidak setuju $(0 \%)$, dan sangat tidak 
setuju ( $0 \%)$. Pernyataan keenam, keutamaan materi lingkungan dalam pembelajaran bahasa Indonesia adalah peserta didik dapat menghargai dan menjaga lingkungan dengan baik, menyatakan setuju $(67,6 \%)$, sangat setuju $(32,4)$, tidak setuju $(0 \%)$, dan sangat tidak setuju $(0 \%)$. Pernyataan ketujuh, lingkungan dapat mengembangkan imajinasi siswa dama pembelajaran bahasa Indonesia, menyatakan setuju (54,5\%), sangat setuju (45,5\%), tidak setuju (0\%), dan sangat tidak setuju (0\%). Pernyataan kedelapan, upaya untuk menjaga kebersihan lingkungan dapat dilakukan dalam proses pembelajaran bahasa Indonesia, menyatakan setuju $(76,5 \%)$, sangat setuju (20,5\%), tidak setuju (2,9\%), dan sangat tidak setuju (0\%). Pernyataan kesembilan, materi lingkungan sangat dibutuhkan untuk diterapkan dalam kehidupan sehari-hari, menyatakan setuju $(67,6 \%)$, sangat setuju (32,4\%), tidak setuju $(0 \%)$, dan sangat tidak setuju $(0 \%)$. Pernyataan kesepuluh, materi lingkungan pada pembelajaran bahasa Indonesia dapat menumbuhkan kepedulian siswa terhadap lingkungan, menyatakan setuju $(52,9 \%)$, sangat setuju $(47,1 \%)$, tidak setuju $(0 \%)$, dan sangat tidak setuju $(0 \%)$.

Berdasarkan hasil penelitian diatas, maka dapat disimpulkan bahwa materi lingkungan sangat penting, khususnya pada pembelajaran bahasa Indonesia. Oleh karena itu, dengan adanya materi lingkungan, peserta didik akan lebih menjaga dan melestarikan lingkungan sekitarnya. Materi lingkungan juga memberikan dampak pada perilaku peserta didik, dengan adanya materi lingkungan ini peserta didik juga lebih peka terhadap kondisi lingkungan, membangun individu peserta didik yang jujur, disiplin, optimis, empati, dan religius. Tulisan ini bertujuan agar masyarakat dan peserta didik dapat menjaga dan melestarikan lingkungan. 


\section{Daftar Rujukan}

Safitri, Annisa, Elfia Sukma. 2020. Peningkatan Hasil Belajar Siswa Pada Tema Menggunakan Pendekatan Saintifik di Sekolah Dasar. Jurnal Pendidikan Tambusai. Volume 4, Nomor 3.

Suardi, Indah Permatasari, Syahrul R, Yasnur Asri. Pemerolehan Bahasa Pertama pada Anak Usia Dini. Jurnal Obsesi : Jurnal Pendidikan Anak Usia Dini. Volume 3 Issue 1 (2019) Pages $265-273$.

Ramadhan, S., Asri, Y., \& Indiryani, V. Learning Module Design Writing Argumentative Text Based Problem-Based Learning. In Advances In Social Science: Education And Humanities Research. Volume 263, Pp. 194-200.

Halawa, Noibe, Erizal Gani, Syahrul R. 2019. Kesantunan Berbahasa Indonesia Dalam Tindak Tutur Melarang dan Mengkritik Pada Tujuh Etnis. Jurnal Lingua. Volume XV. Nomor 2.

Ramadhan, S., Sukma, E., \&Indriyani, V. 2019. Environmental education and disaster mitigation through language learning. IOP Conference Series: Earth and Environmental Science, 314

Angin, Toras Barito Bayo, Syahrul R, Agustina. 2015. Pengembangan Modul Berbasi Pendekatan Kontekstual Pada Menulis Iklan Di Kelas VIII SMP 2

Padangsidipuan Sumatera Utara. Jurnal Bahasa, Sastra dan Pembelajaran. Volume 3 Nomor 1.

Suhatman Jaya, Syahrul R, Ermanto . 2013. Peningkatan Keterampilan Menulis Puisi Melalui Media Gambar Siswa Kelas X.1 Sma Negeri 2 Kota Sungai Penuh . Jurnal Bahasa, Sastra Dan Pembelajaran. Volume 1 Nomor 2,

Sukma, Elfia. 2015. Penerapan Pendekatan Komunikatif Dalam Pembelajaran Struktur Bahasa Indonesia Di Skeolah Dasar. Jurnal Diksi. Vol. 12, No. 1.

Sukma, Elfia. 2016. Kompetensi Kognitif Pembelajaran Apresiasi Sastra Di Sekolah Dasar. Jurnal Gramatika V2. i1 (1-11).

Sukma, Elfia. 2019. Problem in Oral Language Teaching in Primary School. Seventh internation conference on languanges and arts(ICLA2018). Atlantis Press.

SukmaE., S Ramadhan, V Indriyani. 2020. Integration of environmental education in elementary schools. Journal of Physics: Conf. Series1481. 